RESEARCH PAPER

\title{
The effect of islands of improvement on the maturity models for industry 4.0: the implementation of an inventory management system in a beverage factory ${ }^{1,2}$
}

\author{
Sanderson César Macêdo Barbalho1, Rafaela de Faria Dantas² \\ ${ }^{1}$ University of Brasilia, Technology College, Department of Industrial Engineering, Post-graduation Program of Mechatronic \\ Systems, Campus Darcy Ribeiro, Brasilia, DF, Brazil. \\ ${ }^{2}$ Polytechnic University of Milan, Department of Management Engineering, Msc. Program in Industrial Management, Campus \\ La Masa, Milan, Italy.
}

How to cite: Barbalho, S.C.M. and Dantas, R.F. (2021), "The effect of islands of improvement on the maturity models for industry 4.0: the implementation of an inventory management system in a beverage factory", Brazilian Journal of Operations \& Production Management, Vol. 18, No. 3, e20211119.

https://doi.org/10.14488/BJOPM.2021.011

\begin{abstract}
Goal: Industry 4.0 has the main purpose of turning the company into an agile organization and adapting continuously to the market's dynamicity. Thus, to reach this target, the business should be aware of its current readiness level and establish digital strategies to reach higher levels. This research aims to explore how improvements in industry 4.0 can improve companies' business processes.

Design / Methodology / Approach: The present study is action research that initially identified the most suitable maturity model in Industry 4.0 in the scientific and practitioner literature. Furthermore, the chosen model was applied to a beverage manufacturer to evaluate its current maturity level. Some Industry 4.0 improvements were implemented on the warehouse as part of the company's digital strategy into which it was integrated the inventory management system with new digital solutions. Finally, interviews were conducted, and data was gathered from company indicators.

Results: The action research's conduct revealed its current status and how storage management contributed to its digital transformation process. A phenomenon of islands of improvement is discussed at the end.

Limitations of the investigation: Our main limitation is our case study approach. Additionally, more interviews crossing functional areas could bring additional elements about the perception of improvements that each functional group had at the implementation process.

Practical implications: The case study suggests that maturity models' applications can generate the phenomena of islands of improvements. Managers must take this situation into account to plan digital transformation in the whole company.

Originality / Value: The phenomena of the island of improvement is suggested to be a side effect of implementing industry 4.0 based on maturity models.
\end{abstract}

Keywords: Industry 4.0; Maturity Model; Logistics; Inventory; Storage Management Systems; RFID.

\footnotetext{
${ }^{1}$ This article is from the XXVI International Conference on Industrial Engineering and Operations Management (IJCIEOM) and was invited to be published in the September/2021 Special Issue of the Brazilian Journal of Operations \& Production Management, due to its relevance and contribution to the field.

${ }^{2}$ This paper is an expanded version of the final undergraduate project of Rafaela de Farias Dantas, entitled "APLICAÇÃO DO MODELO DE MATURIDADE DE INDÚSTRIA 4.0 EM UMA FABRICANTE DE BEBIDAS E A IMPLEMENTAÇÃO DE UM SISTEMA DE GESTÃO DE ARMAZENAGEM COMO PARTE DE SUA ESTRATÉGIA DIGITAL” which can be acessed on Dantas (2011).
}

Financial support: None.

Conflict of interest: The authors have no conflict of interest to declare.

Corresponding author: sandersoncesar@unb.br

Received: 3 Dec 2020.

Approved: 6 Dec 2020.

Editor: Antônio Márcio Tavares Thomé. 


\section{INTRODUCTION}

In recent years, factors such as the emergence of new technologies coming from different areas, increasing international competition, changes in consumer purchasing habits, and the reduction of product life cycles have significantly increased the complexity of the manufacturing industry (Seidelmann, 2018; Taliaferro et al., 2016, p. 7; Schumacher et al., 2016, p. 162). Digitalization and interconnectivity, and new technologies drive a transformation never seen before in the industry (Schuh et al., 2017, p. 5). This phenomenon is being known as Industry 4.0 (i4.0).

The need to adapt to the new realities imposed by the competitive market requires companies to develop an increasing capacity to plan and manage their operations (Azanha et al., 2016, p. 723). Therefore, they must understand the current maturity level concerning Industry 4.0 and what concrete actions are identified to help them reach higher stages (Schuh et al., 2017, p. 12-13).

Logistics will be affected in two aspects to i4.0: the physical dimension, with the use of collection robots for stock movements, even at the transportation and um-packing steps, and the digital dimension with the collection of machinery data through the internet of things (IoT) sensors, the transmission of this data to cloud and utilization of them for optimizing the process itself (Schuh et al., 2017; Hofmann and Rüsch, 2017, p. 25).

This work fits into this second kind of impact, as it explores the development and implementation of a new and improved storage management system in a beverage manufacturer. The project seeks to answer three questions: how can new technologies improve current and traditional storage management systems? How does the implementation of a storage management system mixed with industry 4.0 technologies contribute to increasing a beverage manufacturer's maturity? And how this level of maturity increment effectively helps a company to improve their business?

In practical terms, the study started assessing the current stage of maturity of a beverage manufacturer, and a new inventory system was planned and implemented. A new maturity analysis allows the discussion of the company's digital strategy for reaching higher competitiveness levels. This profile of implementing industry 4.0 is current in Brazilian companies. Its impact on business can be useful in short-term evaluations but lacks a longterm strategy, impacting company surveillance.

The next section describes the article's main theoretical framework and then discusses the research methods and a presentation of the action research. There are some theoretical and practical considerations regarding the research and the prospects for its further development in section five.

\section{LITERATURE REVIEW}

The term "Industry 4.0" was first introduced in 2011 in Germany to describe the phenomenon of generalized integration of information and communication technology in the industrial context (Schuh et al., 2017, p. 7). It can also be understood as the $4^{\text {Th }}$ industrial revolution.

The main objective of the Fourth Industrial Revolution, according to Schuh et al. (2017, p. 10), is to generate knowledge from data, transform the company into an agile organization, and capable of continually adapting to the dynamics of the market. The dynamic environment and its increasing complexity mean that organizations need to make faster and better decisions if they remain competitive in the long run. Therefore, the real economic potential of i4.0 lies in its ability to accelerate the company's decision-making and adaptation processes (Schuh et al., 2017, p. 10).

The implementation of Industry 4.0 strategies tends to face barriers within companies, mainly because executives are not sure about the results, do not have knowledge about the topic, and commonly the investment is high (Akdil et al., 2018, p. 61-62). Therefore, the maturity models in Industry 4.0 are tools that help managers in decision-making. They provide the means to establish the company's current maturity stage and identify the areas in which 
actions are needed (Schuh et al., 2017, p. 5). According to the authors, the maturity models allow systematic identification of weaknesses and opportunities and provide the basis for formulating a solid implementation strategy for i4.0.

In the literature, some Industry 4.0 maturity models are already found, such as Schuh et al. (2017), Schumacher et al. (2016), Lichtblau et al. (2015), Agca et al. (2017), Ganzarain and Errasti (2016), Akdil et al. (2018). A partial analysis of these models' positive and negative aspects is presented in Silva et al. (2019, p. 1829-1838). They have different approaches and backgrounds for evaluating the companies' easiness for implementing industry 4.0 solutions. Despite the maturity model found, its scientific basis is only starting to be researched. Consequently, a choice can be made for evaluating a company according to the parameters of only one maturity model, in the form of implementing 14.0 solutions systematically.

The main model considered for this study was the proposal of Agca et al. (2017), from Warwick University, which measures the company's maturity through an online questionnaire. It is structured in six dimensions (Products and services, Manufacturing and operations, Strategy and organization, Supply chain, Business model, and Legal considerations) divided into 37 sub-dimensions. Follow an explanation of each dimension.

Products and Services: one of the central pillars of Industry 4.0 is the assumption that a "batch size of 1" can be produced at the same unit cost as a mass-produced product, as customers are believed in the future will appreciate the increasing levels of product customization (Agca et al., 2017, p. 6). According to the authors, a digitally enabled product will also allow the collection of user data, which can be used to offer more valueadded services. It can lead to a business model in which revenue is split between the revenue from the initial purchase of the physical product and the continued revenue from value-added services.

Manufacturing and Operations: the manufacturing process and its operation are the focal points of Industry 4.0. The products will be fully customized and produced autonomously in "auto optimizing" factories (Agca et al., 2017, p. 8). According to the authors, it is an environment in which virtual and physical contexts are integrated and enabled by loT sensors that will allow data collection to plan, optimize, and control physical operation. The optimization is activated through digital modeling using real data. Therefore, this dimension's key criteria are technological integration, autonomous work environment, data, and resource capacity (Agca et al., 2017, p. 8).

Strategy and Organization: In this dimension, the leadership must understand the benefits related to Industry 4.0 and are willing to invest. Successful implementation also requires cross-functional support at both strategic and operational levels, adopting relevant measurements and collaborative ways of working (Agca et al., 2017, p. 10).

Supply Chain: the implementation of Industry 4.0 will provide better visibility of future demand and inventories across the supply chain enabling better forecasting. Real-time information about the product's location, capacity, inventory, and operations will be obtained, allowing sharing information along the value-chain with suppliers and a better response to customer needs (Agca et al., 2017, p. 12).

Business Model: the transformation of products into services has, increasingly, implications for companies' business models ("as a service model") (Agca et al., 2017, p. 14). Such provisions may depend on real-time product tracking and automated, real-time scheduling of maintenance activities Agca et al. (2017) and other kinds of value-added services, according to known or enriched customer needs.

Legal Considerations: as a result of the adoption of Industry 4.0, hiring models are being challenged, particularly traditional models. There is a need for cultural and legal change to adopt more collaborative labor, supplier, and customer agreements, openness to sharing risk and rewards (Agca et al., 2017, p. 16). The generation and flow of data is a fundamental element of Industry 4.0 and a facilitator for creating value.

Unlike other maturity models, Warwick's model describes all the levels for each dimension easily. Consequently, completing the questionnaire becomes more objective for 
the interviewee since he can visualize the required characteristics and correctly position the company about that aspect. It is, consequently, better for comparative analysis.

In general, advanced manufacturing systems, including robotics and automation, are discussed since the '90s under the concept of computer integrated manufacturing (Scheer, 1991). Authors as Schuh et al. (2017) and Schumacher et al. (2016) stated charily that the new phenomena of 14.0 are deeply different from the 90 's incursion on CIM-based factories, because of technology enablers, but also in function of the width of sectors that can be achieved by the digital transformation of business, and the human-technology integration needed.

Despite this, and maybe because of this, a phenomenon discussed in Vernadat (1996) as "performance islands" can happen. Performance islands occur when a serious effort in improvements approach a specific company area. This area's performance tends to advance but is limited by the poor performance of the other areas. As a whole, the system does not reach its possible excellence.

This partial and not general improvement effort is dealt with by the Capability Maturity Model Integration (CMMI). CMMI suggests that it has two possible directions for process improvements based on the third party approaches: a whole company improvement based on maturity levels and a sector-specific improvement approach based on capability assessment (Chrissis et al., 2003). Some literature discusses capability-based improvements Schuh et al. (2017), Barbalho and Rozenfeld (2013), Barbalho and Rozenfeld (2008), but generally, the concept of maturity assessment and improvement is more commonly applied (Schuh et al., 2017; Agca et al., 2017; Carolis et al., 2017). In other words, capability-based improvements tend to generate performance islands, as suggested by Vernadat (1996).

\section{METHOD}

The research methodology adopted for this study was an exploratory and qualitative analysis. It is classified as action research since concepts are investigated in the literature, and there is action by the researcher in a real context (Cauchick Miguel, 2007; Almeida, 2011). For achieving the study goals, it was applied to the methodological procedure proposed by Mello et al. $(2012$, p. 5) on how to conduct action research, as shown in Figure 1.

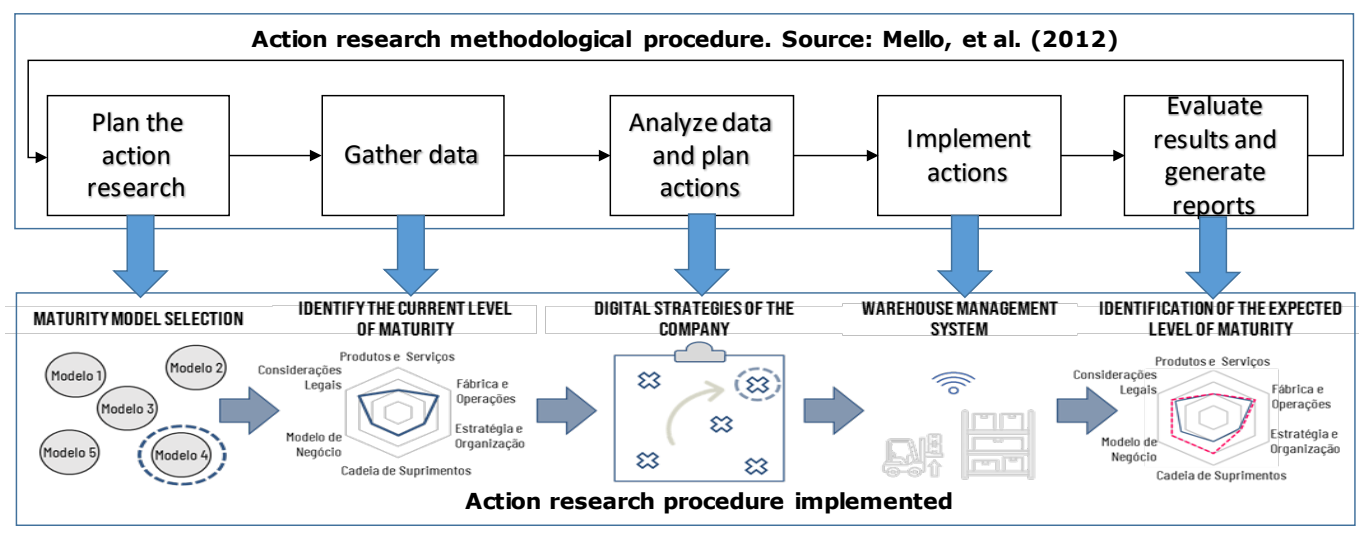

Fig. 1 - Action research methodological procedure. Adapted from Mello et al. (2012).

The action research's specific development followed the structure summarized in Figure 1, and the first stage is a planning phase. This plan was based on the assumption that the best way to implement industry 4.0 improvements through a maturity model. The first step was to define the best maturity model in Industry 4.0 to be used for the analysis of the case studied, based on the models raised in the literature review.

The Analytical Hierarchy Process (AHP) was adopted due to many criteria for choosing the maturity model and its subjectivity, difficult to measure. Besides, some maturity model alternatives raised needed to be ranked. 
The AHP method was introduced by Saaty and is an effective tool for dealing with complex decisions. It assists decision-makers in setting priorities and makes the best decision. It is done by structuring a criteria hierarchy and identifying the relative weights' values so that they can match an established strategy (Cantamessa and Montagna, 2016). According to the authors, the AHP performs this weighting of criteria, evaluates alternatives through pairwise comparisons, and then validates the overall results.

According to Saaty e Vargas (2012), the analysis process considers the following steps:

1. Definition of the general objective;

2. Clear definition of the analysis criteria;

3. Set priorities for the main criteria associating relative weights to them and generation of a reciprocal matrix of pairwise comparison, based on the scale of judgments presented in Table 1;

Table 1 - The fundamentals scale for pairwise comparison. Source: Adapted from Saaty (1987).

\begin{tabular}{cll}
\hline $\begin{array}{c}\text { Degree of } \\
\text { importance }\end{array}$ & \multicolumn{1}{c}{ Definition } & \multicolumn{1}{c}{ Description } \\
\hline 1 & Equal importance & Two elements contribute equally to the objective \\
\hline 3 & Moderate importance & $\begin{array}{l}\text { Experience and judgment slightly favor one element } \\
\text { over the other }\end{array}$ \\
\hline 5 & Strong importance & $\begin{array}{l}\text { Experience and judgment strongly favor one element } \\
\text { over the other }\end{array}$ \\
\hline 7 & Very strong importance & $\begin{array}{l}\text { One element is strongly favored over the other, and its } \\
\text { dominance is evidenced in practice }\end{array}$ \\
\hline 9 & Extremely important & $\begin{array}{l}\text { The evidence of the dominance of one element over } \\
\text { the other is of the highest degree of certainty }\end{array}$ \\
\hline Intensities of values 2,4,6, and 8 can be used to express intermediate values.
\end{tabular}

4. Eigenvector calculation (see Table 4), given by the geometric mean of each of the criteria, to identify their relative importance, as shown in Equation 1, where $\mathrm{W}$ is the eigenvector, $\mathrm{C}$ is the criteria, $\mathrm{n}$ is the number of criteria.

$W_{i}=\sqrt[n]{C 1^{*} C 2^{*} C 3^{*} C n}$

5. Normalization of Eigenvectors given by the Equation 2

$W_{i}^{*}=\frac{W i}{\sum_{i=1}^{n} W i}$

6. Consistency Index $(\mathrm{Cl})$ calculation given by Equation 3 verifies whether there is consistency in the value of the judgments given. Where the factor $\lambda_{\max }$ is the largest eigenvalue, calculated through the adding of each criterion column and by multiplying the normalized eigenvector; $\mathrm{n}$ is the number of criteria.

$C I=\frac{\lambda_{\max x-n}}{n-1}$

7. Consistency Ratio (CR) calculation is given by Equation 4, where $\mathrm{Cl}$ is the Consistency Index calculated in Equation 3, and RI is the Random Index stipulated by Table 2. If the value found is $<10 \%$, the judgments were consistent. 
$C R=\frac{C I}{R I}$

Table 2 - Average random consistency index. Source: Adapted Saaty and Vargas (2012).

\begin{tabular}{cllllllllll}
\hline $\mathbf{n}$ & $\mathbf{1}$ & $\mathbf{2}$ & $\mathbf{3}$ & $\mathbf{4}$ & $\mathbf{5}$ & $\mathbf{6}$ & $\mathbf{7}$ & $\mathbf{8}$ & $\mathbf{9}$ & $\mathbf{1 0}$ \\
\hline Random consistency index $(\mathrm{RI})$ & 0 & 0 & 0.52 & 0.89 & 1.11 & 1.25 & 1.35 & 1.40 & 1.45 & 1.49 \\
\hline
\end{tabular}

8. Check the criteria for each alternative, following steps 4, 5, 6, 7;

9. Calculation of results to obtain final priorities (decision vector). The decision vector is calculated by multiplying the alternatives matrix's results by the criteria eigenvector's results, according to Equation 5.

$D V_{i j}=A 1^{*} C 1+A 1^{*} C 2+A 1 * C 3+\ldots+A_{i}^{*} C_{j}$

According to the next sections' analysis, the AGCA model was chosen (Agca et al., 2017). The second stage consisted of gathering data for applying the AGCA model to identify the beverage manufacturer's current maturity. For doing this, meetings were conducted with the Commercial, Logistics, Industrial Engineering, Financial, Supplies, and IT areas. With 37 questions, the questionnaire was filled out together with the managers to answer possible doubts during the application. Although the questionnaire was divided into departments, all questions were revisited by all leaders to ratify the answers.

Then, we sought to understand what digital strategies were underway in the company to reach a higher level of maturity in Industry 4.0 (third stage - Figure 1). The company already had a consistent digital assessment and automatization on its manufacture área, and other areas were in a way to implement a computerized-based management system. Thus, some meetings were carried out with the managers of manufacturing and logistics, and it was decided to study the process of implementing a storage system. As the company chooses to implement improvements in only one area, the researchers define a research protocol to gather at the end of the appliance the same data they gathered in the beginning for comparison.

The fourth stage (Figure 1) consisted of implement improvements in an area chosen by company decision-makers. The material entry area was selected to implement the project. The first stage consisted of contextualizing the company, characterizing the stock, and operating its storage structures. Through the Bizagi process mapping tool, the storage process was portrayed before and after implementing the management system. Finally, the system requirements were described, and its operation was detailed. This period lasted three months, and one of the authors worked directly on implementing daily meetings with company personnel. Weekly meetings were done between researchers to analyze and align the scientific method to the hands-on activities.

The fifth stage was to study the implementation process of an inventory management system and to understand what results and benefits this project would bring to the company on the lights of industry 4.0 literature. In this stage, the results were evaluated. Therefore, the quantitative and qualitative results presented by the management system were measured. The maturity model has been applied again for diagnosing the dimensions that underwent changes and how much they impacted the overall company's maturity. The report generated on this stage originated in this article.

\section{RESULTS AND DISCUSSION}

The study was conducted at a beverage manufacturer and distributor. The products sold include more than 200 SKU's (Stock Keeping Unit) and are divided into sparkling products 
(carbonate), still (juices, teas, and energy drinks), and beers. Other companies manufacture the last two, and the company is only responsible for storing, marketing, and distributing.

\subsection{The choice for a maturity model}

This section will expose how the AHP method was applied to select the best maturity model in Industry 4.0. The steps presented in the methodology sections were carried out. According to our literature review, five maturity models in Industry 4.0 were taken into account:

Model 1- Industrie 4.0 Maturity Index - Acatech Study - (Schuh et al., 2017),

Model 2- A maturity model for assessing industry 4.0 readiness and maturity of manufacturing enterprises - (Schumacher et al., 2016)

Model 3- Industrie 4.0 readiness - IMPULS - (Lichtblau et al., 2015)

Model 4- An Industry 4 readiness assessment tool - WMG; Crimson \& Co; Pinsent Masons (Agca et al., 2017)

Model 5- Maturity and Readiness Model for Industry 4.0 Strategy (Akdil et al., 2018)

The steps of AHP were performed, according to:

1. Definition of the general objective

The general objective of applying the AHP method is to choose the best maturity model in Industry 4.0 to be applied in this research.

2. Clear definition of the analysis criteria;

The following criteria were defined for choosing the maturity model using the AHP: Clear methodology (C1); Questionnaire available (C2); Number of maturity levels (C3); Structure of the questions (C4); Answers that contain the description of each maturity level (C5).

Criterion 1 - Clear methodology. At this point, it will be evaluated if the author's methodology is well clarified and reasoned and if the author presents a method for calculating each maturity dimension.

Criterion 2 - Questionnaire available. It is not part of this work's scope to create or adapt a questionnaire to measure the level of maturity in Industry 4.0. Thus, it is essential that a questionnaire be available to measure the maturity level in the model proposed.

Criterion 3 - Number of maturity levels. In this criterion, the lower the number of maturity levels proposed by the model, the lower the precision level regarding the company's reality. Therefore, if the enterprise decides to apply new technologies and improvements to achieve a higher maturity level if the model proposed contains few precision levels, the company can probably continue at the same level after the changes are implemented and not notice any kind of progress. On the other hand, if the model contains more maturity levels, the company will perceive gradual advances based on the improvements implemented.

Criterion 4 - Structure of the questions. This criterion takes into account the way and the easiness that questions are constructed. The points that composed the answer to these questions must be structured hierarchically. In other words, each topic of the answer should address the level of maturity proposed in the methodology. Moreover, the questionnaire should not contain "yes" or "no" questions since this type of answer makes it difficult to measure maturity.

Criterion 5 - Answers with a description of each maturity level. If the answers contain the levels described for each dimension, completing the questionnaire becomes more objective for the interviewee since he can visualize the required characteristics and correctly position the company concerning that aspect.

3. Set priorities for the main criteria associating relative weights to them and generation of a reciprocal matrix of pairwise comparison (see Table 3), based on the scale of judgments presented in Table 1; 
Table 3 - Judgement matrix. Source: Authors, (2019).

\begin{tabular}{cccccc}
\hline & C1 & C2 & C3 & C4 & C5 \\
\hline C1 & 1 & $1 / 7$ & 3 & 1 & $1 / 3$ \\
C2 & 7 & 1 & 9 & 5 & 5 \\
C3 & $1 / 3$ & $1 / 9$ & 1 & $1 / 3$ & 1 \\
C4 & 1 & $1 / 5$ & 3 & 1 & $1 / 3$ \\
C5 & 3 & $1 / 5$ & 1 & 3 & 1 \\
\hline Total: & $\mathbf{1 2 . 3 3}$ & $\mathbf{1 . 6 5}$ & $\mathbf{1 7 . 0 0}$ & $\mathbf{1 0 . 3 3}$ & $\mathbf{7 . 6 7}$ \\
\hline
\end{tabular}

4. Eigenvector calculation

5. Normalization of Eigenvectors

Table 4 - Eigenvect calculation and normalization. Source: Authors, (2019).

\begin{tabular}{cccccccc}
\hline & C1 & C2 & C3 & C4 & C5 & Eigenvector & Normalization \\
\hline C1 & 1 & $1 / 7$ & 3 & 1 & $1 / 3$ & 0.678 & $\mathbf{9 . 3 \%}$ \\
\hline C2 & 7 & 1 & 9 & 5 & 5 & 4.360 & $\mathbf{5 9 . 7 \%}$ \\
C3 & $1 / 3$ & $1 / 9$ & 1 & $1 / 3$ & 1 & 0.415 & $\mathbf{5 . 7 \%}$ \\
\hline C4 & 1 & $1 / 5$ & 3 & 1 & $1 / 3$ & 0.725 & $\mathbf{9 . 9 \%}$ \\
\hline C5 & 3 & $1 / 5$ & 1 & 3 & 1 & 1.125 & $\mathbf{1 5 . 4 \%}$ \\
\hline Total: & $\mathbf{1 2 . 3 3}$ & $\mathbf{1 . 6 5}$ & $\mathbf{1 7 . 0 0}$ & $\mathbf{1 0 . 3 3}$ & $\mathbf{7 . 6 7}$ & $\mathbf{7 . 3 0 2}$ & $\mathbf{1 0 0 \%}$ \\
\hline
\end{tabular}

6. Consistency Index $(\mathrm{Cl})$ calculation

$C I=\frac{5.31-5}{5-1}=0.087$

7. Consistency Ratio (CR) calculation

$C R=\frac{0.087}{1.11}=7.84 \%$

Since the CR value is less than $10 \%$, the weights given to the criteria are consistent. From the results found, it is observed that criterion 2 (questionnaire available) was the one with the greatest weight (59.7\%). This value is consistent since, without the questionnaire, it would not be possible to apply the maturity model in Industry 4.0.

8. Check the criteria for each alternative, following steps 4, 5, 6, 7;

For each criterion, an evaluation was carried out regarding the model alternatives. Tables 5, 6, 7, 8, 9 illustrate the procedure performed.

Table 5 - Pairwise matrix concerning maturity model alternatives with C1. Source: Authors, (2019).

\begin{tabular}{cccccccc}
\hline $\begin{array}{c}\text { C1 - Clear } \\
\text { methodology }\end{array}$ & A1 & A2 & A3 & A4 & A5 & Eigenvector & Normalization \\
\hline A1 & 1 & 5 & 3 & 3 & 7 & 3.160 & $\mathbf{4 7 . 1 \%}$ \\
\hline A2 & $1 / 5$ & 1 & $1 / 3$ & 1 & 5 & 0.803 & $\mathbf{1 2 . 0 \%}$ \\
\hline A3 & $1 / 3$ & 3 & 1 & 1 & 5 & 1.380 & $\mathbf{2 0 . 6 \%}$ \\
\hline A4 & $1 / 3$ & 1 & 1 & 1 & 5 & 1.108 & $\mathbf{1 6 . 5 \%}$ \\
\hline A5 & $1 / 7$ & $1 / 5$ & $1 / 5$ & $1 / 5$ & 1 & 0.258 & $\mathbf{3 . 8 \%}$ \\
\hline Total: & $\mathbf{2 . 0}$ & $\mathbf{1 0 . 2}$ & $\mathbf{5 . 5}$ & $\mathbf{6 . 2}$ & $\mathbf{2 3 . 0}$ & $\mathbf{6 . 7 0 8}$ & $\mathbf{1 0 0 . 0 \%}$ \\
\hline
\end{tabular}


Table 6 - Pairwise matrix concerning maturity model alternatives with C2. Source: Authors, (2019).

\begin{tabular}{cccccccc}
\hline $\begin{array}{c}\text { C2 }- \\
\begin{array}{c}\text { Questionnaire } \\
\text { available }\end{array}\end{array}$ & A1 & A2 & A3 & A4 & A5 & Eigenvector & Normalization \\
\hline A1 & 1 & 1 & $1 / 5$ & $1 / 9$ & $1 / 7$ & 0.316 & $\mathbf{4 . 4 \%}$ \\
A2 & 1 & 1 & $1 / 5$ & $1 / 9$ & $1 / 7$ & 0.316 & $\mathbf{4 . 4 \%}$ \\
\hline A3 & 5 & 5 & 1 & 5 & $1 / 3$ & 2.108 & $\mathbf{2 9 . 6 \%}$ \\
\hline A4 & 9 & 9 & $1 / 5$ & 1 & 5 & 2.408 & $\mathbf{3 3 . 8 \%}$ \\
A5 & 7 & 7 & 3 & $1 / 5$ & 1 & 1.966 & $\mathbf{2 7 . 6 \%}$ \\
Total: & $\mathbf{2 3 . 0}$ & $\mathbf{2 3 . 0}$ & $\mathbf{4 . 6}$ & $\mathbf{6 . 4}$ & $\mathbf{6 . 6}$ & $\mathbf{7 . 1 1 6}$ & $\mathbf{1 0 0 \%}$ \\
\hline
\end{tabular}

Table 7 - Pairwise matrix concerning maturity model alternatives with C3. Source: Authors, (2019).

\begin{tabular}{cccccccc}
\hline $\begin{array}{c}\text { C3 - Number of } \\
\text { maturity levels }\end{array}$ & A1 & A2 & A3 & A4 & A5 & Eigenvector & Normalization \\
\hline A1 & 1 & 3 & 3 & 5 & 7 & 3.160 & $\mathbf{4 6 . 6 \%}$ \\
\hline A2 & $1 / 3$ & 1 & 1 & 3 & 5 & 1.380 & $\mathbf{2 0 . 3 \%}$ \\
\hline A3 & $1 / 3$ & 1 & 1 & 3 & 5 & 1.380 & $\mathbf{2 0 . 3 \%}$ \\
\hline A4 & $1 / 5$ & $1 / 3$ & $1 / 3$ & 1 & 3 & 0.582 & $\mathbf{8 . 6 \%}$ \\
A5 & $1 / 7$ & $1 / 5$ & $1 / 5$ & $1 / 3$ & 1 & 0.286 & $\mathbf{4 . 2 \%}$ \\
\hline Total: & $\mathbf{2 . 0}$ & $\mathbf{5 . 5}$ & $\mathbf{5 . 5}$ & $\mathbf{1 2 . 3}$ & $\mathbf{2 1 . 0}$ & $\mathbf{6 . 7 8 7}$ & $\mathbf{1 0 0 \%}$ \\
\hline
\end{tabular}

Table 8 - Pairwise matrix concerning maturity model alternatives with C4. Source: Authors, (2019).

\begin{tabular}{|c|c|c|c|c|c|c|c|}
\hline $\begin{array}{c}\text { C4 - Structure } \\
\text { of the } \\
\text { questions }\end{array}$ & A1 & A2 & A3 & A4 & A5 & Eigenvector & Normalization \\
\hline A1 & 1 & 3 & 7 & $1 / 5$ & 5 & 1.838 & $22.3 \%$ \\
\hline$A 2$ & $1 / 3$ & 1 & 5 & $1 / 7$ & 5 & 1.035 & $12.5 \%$ \\
\hline A3 & $1 / 5$ & $1 / 5$ & 1 & $1 / 9$ & $1 / 3$ & 0.272 & $3.3 \%$ \\
\hline A4 & 5 & 7 & 9 & 1 & 7 & 4.663 & $56.5 \%$ \\
\hline A5 & $1 / 5$ & $1 / 5$ & 3 & $1 / 7$ & 1 & 0.443 & $5.4 \%$ \\
\hline Total: & 6.7 & 11.4 & 25.0 & 1.6 & 18.3 & 8.252 & $100 \%$ \\
\hline
\end{tabular}

Table 9 - Pairwise matrix concerning maturity model alternatives with C4. Source: Authors, (2019).

\begin{tabular}{cccccccc}
\hline $\begin{array}{c}\text { C5 }- \text { Answers } \\
\text { that contain } \\
\text { the description } \\
\text { of each } \\
\text { maturity level }\end{array}$ & A1 & A2 & A3 & A4 & A5 & Eigenvector & Normalization \\
\hline A1 & 1 & 7 & 5 & $1 / 5$ & 3 & 1.838 & $\mathbf{2 3 . 7 \%}$ \\
\hline A2 & $1 / 7$ & 1 & $1 / 3$ & $1 / 7$ & $1 / 5$ & 0.267 & $\mathbf{3 . 5 \%}$ \\
\hline A3 & $1 / 5$ & 3 & 1 & $1 / 7$ & $1 / 3$ & 0.491 & $\mathbf{6 . 3 \%}$ \\
A4 & 5 & 7 & 7 & 1 & 5 & 4.146 & $\mathbf{5 3 . 5 \%}$ \\
\hline A5 & $1 / 3$ & 5 & 3 & $1 / 5$ & 1 & 1.000 & $\mathbf{1 2 . 9 \%}$ \\
\hline Total: & $\mathbf{6 . 7}$ & $\mathbf{2 3 . 0}$ & $\mathbf{1 6 . 3}$ & $\mathbf{1 . 7}$ & $\mathbf{9 . 5}$ & $\mathbf{7 . 7 4 3}$ & $\mathbf{1 0 0 \%}$ \\
\hline
\end{tabular}


Regarding the first criterion (C1), the model proposed by the authors Schuh et al. (2017) stood out because, because, besides having the descriptions of each of the stages of maturity in Industry 4.0 like the other models, it also presents a structured model that allows it to be applied in different functional areas of the company. Another relevant point is that, after the diagnosis of the current stage of maturity, the methodology proposes identifying the capacities and resources that need to be developed and developing a roadmap with digital strategies to reach the highest level of maturity desired by the company.

The second criterion (C2), considered the most critical one, concerns the questionnaire's availability. Models 1 and 2, despite the positive highlight of the methodology, do not have questionnaires available. Models 3, 4, 5 received a similar score for having questionnaires, emphasizing model 4 , which presented the most structured and applicable to the reality of the action research accomplished in the company since it was intended for medium and large manufacturing companies.

The third criterion (C3) refers to the number of levels of maturity that the model presents. Again, Model 1, proposed by Schuh et al. (2017), received the highest score because it has the highest number of levels ( 6 in total).

Table 8 presents the criteria (C4). Model 4 was the leader in this category, as it was the study that presented the questionnaire that had the easiest questions to understand. Also, according to their proposed maturity levels, responses were structured in hierarchies, with the description of each level. Models 1 and 2 also had a good score because, in the authors' question, the answers were also hierarchical and easy to understand. Models 3 and 5 contained questions that did not have a clear purpose, which caused difficulties in interpreting the interviewee during the questionnaire's application. Besides, they also had some "yes" or "no" questions.

Finally, the last criterion (C5) sought to assess whether the answers to the questionnaire questions were in a hierarchical format and present each maturity level's description. Model 4 was the only one that had the complete questionnaire and following this format. Model 1 also received a relevant score because, in the authors' example question, the levels were also hierarchical and described. Model 2 had the worst score because, despite being hierarchical, it was up to the interviewee to identify the company's level regarding that dimension of industry 4.0, making the questionnaire responses very subjective.

9. Calculation of results to obtain final priorities (decision vector) according to Table 10 .

Table 10 - Decision-making matrix. Source: Authors, (2019).

\begin{tabular}{ccccccc}
\hline & $\mathbf{C 1}$ & $\mathbf{C 2}$ & $\mathbf{C 3}$ & $\mathbf{C 4}$ & $\mathbf{C 5}$ & Decision-making vector \\
\hline $\begin{array}{c}\text { Eigenvector } \\
\text { normalizad } \\
\text { considering } \\
\text { the crierias }\end{array}$ & $\mathbf{9 . 3 \%}$ & $\mathbf{5 9 . 7 \%}$ & $\mathbf{5 . 7 \%}$ & $\mathbf{9 . 9 \%}$ & $\mathbf{1 5 . 4 \%}$ & $\mathbf{1 0 0 . 0 \%}$ \\
A1 & $47.1 \%$ & $4.4 \%$ & $46.6 \%$ & $22.3 \%$ & $23.7 \%$ & $15.54 \%$ \\
\hline A2 & $12.0 \%$ & $4.4 \%$ & $20.3 \%$ & $12.5 \%$ & $3.5 \%$ & $6.70 \%$ \\
\hline A3 & $20.6 \%$ & $29.6 \%$ & $20.3 \%$ & $3.3 \%$ & $6.3 \%$ & $22.06 \%$ \\
\hline A4 & $16.5 \%$ & $33.8 \%$ & $8.6 \%$ & $56.5 \%$ & $53.5 \%$ & $36.08 \%$ \\
A5 & $3.8 \%$ & $27.6 \%$ & $4.2 \%$ & $5.4 \%$ & $12.9 \%$ & $19.62 \%$ \\
\hline
\end{tabular}

Although Model 1 was the leader in some criteria, Model 4, by Agca et al. (2017), was chosen as the best to be applied in action research, resulting from $36.08 \%$. It meets the two main requirements: availability of the questionnaire (59.7\%) and responses with a description 
of each maturity level (15.4\%). Model 3 has the second-best score. However, despite having a very grounded methodology, when analyzing the questionnaire, it was noted that there were some very simple questions and that they were not structured as expected, as there was no standardized form of calculation available.

\subsection{Process of implementing the storage management improvements based on the chosen maturity model}

The model was chosen to conduct the company's action research was the proposal of Agca et al. (2017). The first step consisted of the translation of the questionnaire. Then, the six dimensions were divided between the company's corresponding areas to facilitate the application process. A set of meetings was carried out.

\subsubsection{Diagnosing the previous maturity level for industry 4.0 in the company}

The company's overall maturity results concerning Industry 4.0 were 2.12 out of 4 , being considered "Intermediate" on the authors' proposed scale, as shown in Figure 2.

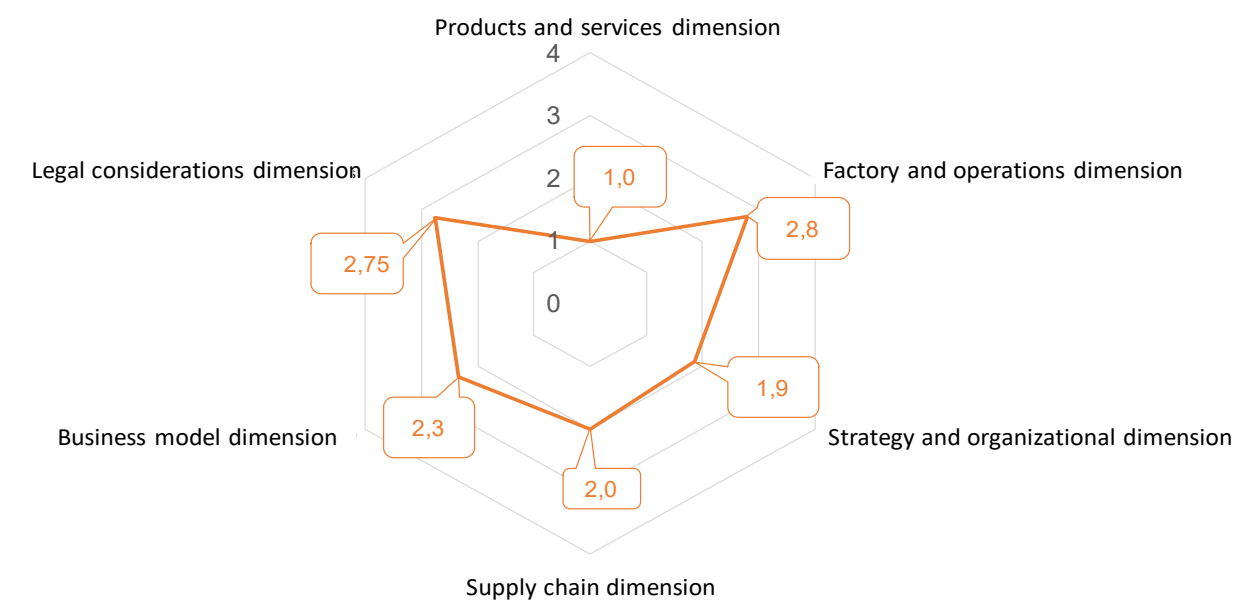

Fig. 2 - Maturity by model dimension at the beginning of process improvement effort. Source: Authors, (2019).

The first dimension assessed was "Products and Services". The product manufactured by the company is a consumer good that has only physical value. Unlike electronic devices, for example, the product does not yet have a production process that allows personalization or user data to be collected through its use.

The next dimension was "Manufacturing and Operations", which got the highest score in our evaluation (2.8). Most of the machinery related to the main production process can be controlled through automation. Besides, the machines and systems are partially integrated; it is estimated that $98 \%$ of the production data is collected and controlled in a digital and automated way. All machines have a PLC (Programmable Logic Controller) device that allows installing programs to collect and monitor data from production lines. Therefore, if a change in the machinery would be necessary to meet Industry 4.0, this change can be easily scheduled.

Then the dimension of "Strategy and Organization" was evaluated, which obtained a score of 1.9 out of 4 . 14.0 is already included in the company's business strategy. In 2019, a reformulation in the strategic map was inserted as one of its pillars: "increase productivity and quality in processes through innovation and a more agile and digital work model". This vision is on the background of the project here presented.

The "Supply Chain" dimension received a score of 2 for all sub-dimensions. The inventory control process currently uses the computer database; however, it is still updated manually. Regarding the integration of the supply chain, there is basic communication to customers and suppliers, and data sharing is done when requested and mainly against claims. 
The dimension of "Business Model" received an overall score of 2.3 out of 4. Product tracking along the value chain is limited. There is no effective movement control of products within the warehouse, and the gathering data from the product life cycle is not on the companies' horizon. Consequently, nothing is known about possible life cycle business the company could exploit.

Finally, the last dimension evaluated was Legal Considerations, which presented an average of 2.75 out of 4. All areas have a risk and risk map related to the processes directly linked to the goals and the varied remuneration for laborers given at the end of the year. There are robust policies and procedures for data protection, but not updated with the General Data Protection Regulation.

\subsubsection{Implementation of the industry 4.0 storage management system}

The project to implement an inventory management system came intending to track product movements and bring intelligence to the storage process. Previously to this system, the forklift operator had the autonomy to choose which address was most convenient for storing a pallet. However, the fact that the employee did not have an overview of the production and delivery schedule led to poor use of street spaces in the warehouse. Sometimes, there was no time available to dismantle the streets according to a first-to-expirefirst-out (FEFO) logic; consequently, the same product was stored in different locations. The products became much more susceptible to losing their shelf-life (FEFO breaks).

Figure 3 summarizes the solutions designed for the new system. They are: data collector, labeled pallets, and a unique warehouse addressing well-identified. The system as a whole operates in four steps:

- For every pallet, before its storage, a label is generated in the system with shelf-life information, product code, product description, and the number of boxes. Then the label is glued to the pallet in question;

- The stacker selects the "Entry" option using the data collector and selects the address where the pallet will be stored. This address was previously programmed by the inventory controller team (Figure 4).

\section{DATA GATHERING SYSTEM}

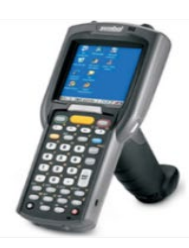

LABELLED PALLET

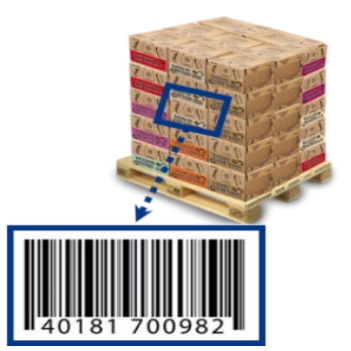

\section{UNIQUE LABELLED ADDRESS}

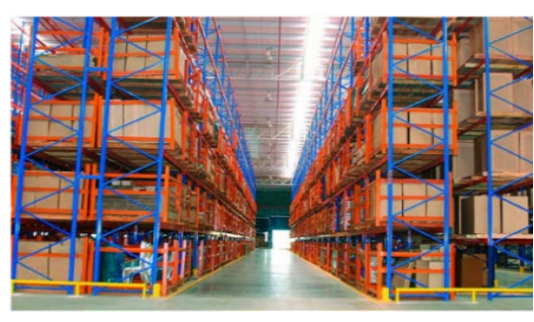

Fig. 3 - Solutions for the inventory management system. Source: Authors, (2019).

- The stacker then "beeps" the barcode on the pallet label and the barcode on the label that identifies the stock's shelf address where the pallet will be stored, as shown in Figure 5.

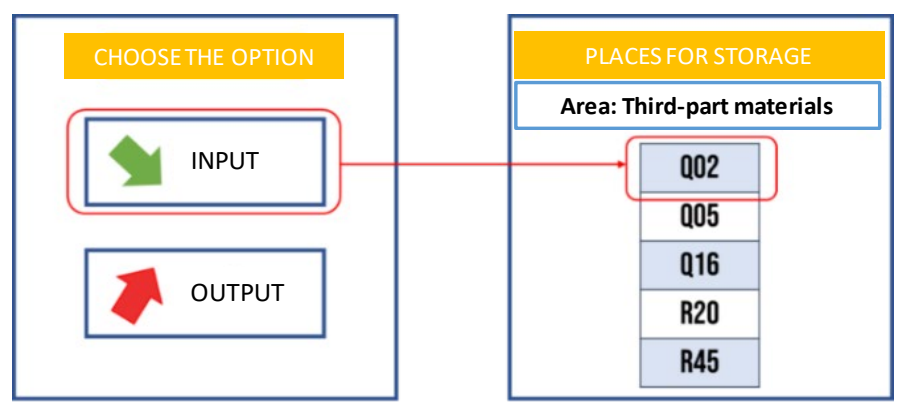

Fig. 4 - Process of data entry on the collector. Source: Primary data, authors, (2019). 


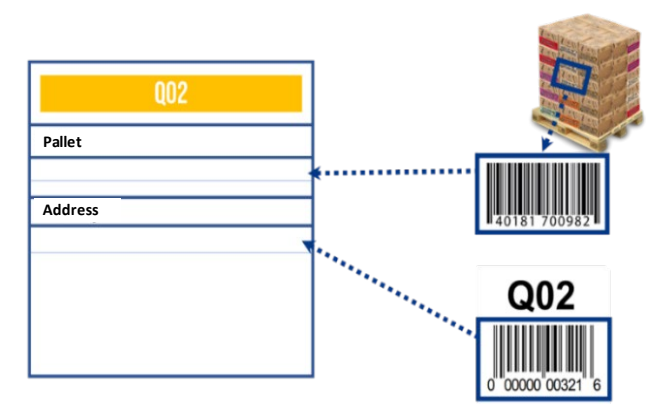

Fig. 5 - Pallet identification on shelf addresses. Source: Primary data, authors, (2019).

- In the end, when products from that pallet will be picking for attending an order or for the picking buffer (intermediate inventory), the stacker receives a schedule from the controllers. He selects the "Exit" button and goes to the address where the pallet is located, takes the pallet, and "beep" to write off the product in the system (Figure 6).

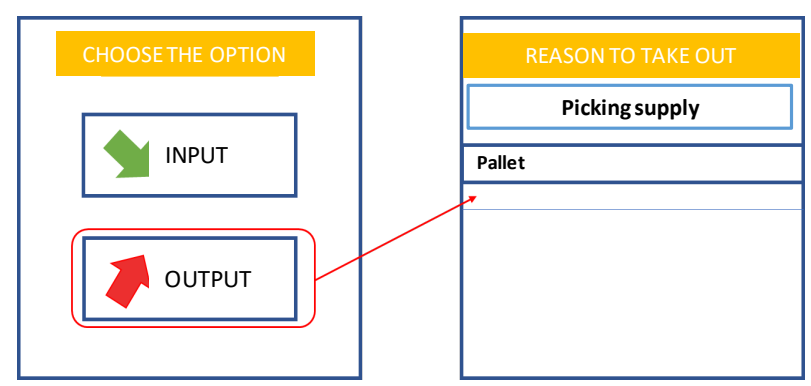

Fig. 6 - Exit of the pallet from storage. Source: primary data, authors (2019).

The storage scheduling process was also designed. Through the management system, the inventory controllers would be able to overview the products already stored, as seen in Figure 7. Therefore, one day before the picking trucks' arrival to fulfill customer orders, they would be responsible for selecting the best warehouse addresses to be used for these deliveries. Doing this, they would inform in advance which streets would need to be dismantled, making better use of the forklift trucks' free working windows and preparing the storage structures for the arrival of newly manufactured products.

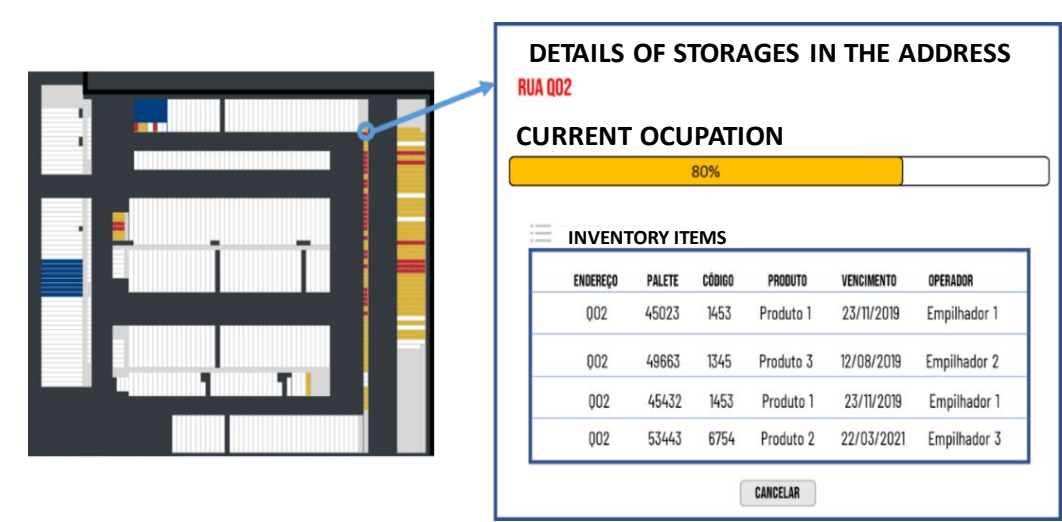

Fig. 7 - Warehouse layout and detail of the selected address. Source: Authors, (2019).

Also, according to Figure 7, when selecting a street, a screen opens with the details of the stores in that address within the system. The information presented is which pallets are stored in it, their respective codes, the product description, the expiration date of each one, and the operator responsible for the initial storage. In Figure 7, the street under analysis is Q02, and it is noted that its current occupation is $80 \%$. Besides, there are three different types of products 
stored on it, with different expiration dates and the operator's identification responsible for storing that pallet.

Thus, if there is a break in the FEFO rule, it is possible to identify the responsible operator and request the street's correction in advance.

\subsubsection{Results of systems' implementation}

Table 11 summarizes the results of the implementation of the management system.

Table 11 - Storage parameters before and after improvements. Source: Authors, (2019).

\begin{tabular}{|c|c|c|}
\hline Parameter & Before & After \\
\hline $\begin{array}{l}\text { Loss of pallets for failure to comply with the } \\
\text { FEFO rule (in BLR) }\end{array}$ & $-4.000 \mathrm{BRL}{ }^{*}$ & $+2.500 B R L^{\star \star}$ \\
\hline Average storage time for a 36 pallets street & $1 \mathrm{~h} 42 * \star *$ & 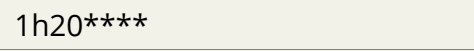 \\
\hline Storage intelligence & Inexistent & $\begin{array}{l}\text { Control and traceability of all } \\
\text { products in the third party } \\
\text { receiving area }\end{array}$ \\
\hline Inventory control & Manual & Automatically \\
\hline Control of critical items & Manual & Automatically \\
\hline
\end{tabular}

In three months (before implementation), the value of pallets lost due to stacker error when storing it was verified. In this period, some pallets had to be discarded. They expired in the stock due to the inversion of dates during storage, summing up a loss of approximately 4,000 BRL.

In the next three months, with the system in progress, the same indicator was calculated. In the report of critical items issued by the system, products stored incorrectly, breaking the FEFO rule, were identified. In advance, forklift operators were asked to reorder the street, which saved the company $2,500 \mathrm{BRL}$ (the value of pallets that avoided being discarded).

Another indicator raised was the average storage time of a street containing 36 pallets. Without the system, the forklift operator would dismantle a quarter of the street before starting storage to comply with the FEFO rule. With the new process, by the time the forklift operator was going to supply the streets, they were already empty, reducing the average storage time by 22 minutes on average. Throughout the day, around 132 minutes were saved per forklift. Therefore, it is an annual saving for the company of 126,225 BRL as a result of the increase in labor productivity.

Another improvement was controlling and tracking all pallets from the unloading process to picking them up to the customer. Also, inventory control was no longer manual and started to be done through reports issued by the system.

\subsubsection{The final level of maturity}

The last part of the action research consisted of applying the maturity model again, talking to the same personnel interviewed at the beginning of the improvement. As a result, two dimensions changed after implementing the new inventory system, see Table 12 . The first one was the "Supply Chain", which went from 2 to 2.6 (30\% improvement) since the inventory control started to use smart devices, increasing the supply chain visibility. And the second dimension was that of the "Business Model" from 2.3 to 2.5 (improvement of 20\%) since the system provided pallet traceability. 
Table 12 - Maturity index on the final of process improvements. Source: Authors, (2019).

\begin{tabular}{lccc}
\hline \multicolumn{1}{c}{ Dimensions } & Before & After & Improvement (\%) \\
Products and services & 1.0 & 1.0 & $0 \%$ \\
\hline Manufacture and operations & 2.8 & 2.8 & $0 \%$ \\
\hline Strategy and organization & 1.9 & 1.9 & $0 \%$ \\
\hline Supply chain & 2.0 & 2.6 & $30 \%$ \\
\hline Business models & 2.3 & 2.5 & $9 \%$ \\
\hline Legal considerations & 2.75 & 2.75 & $0 \%$ \\
\hline General & 2.1 & 2.3 & $9.5 \%$ \\
\hline
\end{tabular}

\subsection{Discussion}

The project carried out for improving the company's storage would bring more productivity in the areas of production planning and control, and logistics itself, and more specifically, the picking process, a typical MTS-based improvement as stated by Carolis et al. (2017). Taking the chosen maturity model into account could impact the area of "products and services" once customers can be connected to companies' stocks and order directly from the available SKUs. For "Manufacturing and Operations", good warehouse management can optimize production orders according to possible storage breaks. The dimension "strategy and organization" could be benefited from the easiness of integrating the whole supply chain. As a dimension, the "supply chain" can be better balanced if demand forecasting would be integrated into storage control. New "business models" can be enabled by offering the customers the real-time position of companies' storage. Finally, "legal considerations" can be supported to deal with new agreements with both customers and suppliers.

Only supply chain and business models are transparent to the company managers from all of these possible improvements. It can mean a low level of digital capability (Schuh et al., 2017) as understood by company personnel, once the other areas are not explicitly presented as possible improvement focus by interviewed managers. Here it is important to contemporize the analysis's subjectivity once each interviewed manager has his interests, technical and organizational backgrounds, and mindset. These elements get some bias to the evaluation of improvement projects, as discussed in Barbalho and Rozenfeld (2010).

Despite this, the general improvement percentage was 9,5\%, but what it can mean to the company? Does an improvement in the supply chain impact a company as an increment on strategy and organization, for example? Or in the products and services dimension? Or yet on issues of manufacturing and operations? The contextual assessment issue is approached in Colli et al. (2018) and opens horizons for research.

Moreover, is it not necessarily be specific to the company's demands for describing maturity improvements (Colli et al., 2019)? As mentioned, all areas of the maturity model approached could reap results from the technologies implemented, but the company needs to be integrated to achieve these results. If one looks at the shy improvement of $9.5 \%$ can question if the kind of technology of industry 4.0 could disrupt company competitiveness. But, as discussed by Schuh et al. (2017), technologies are only enablers for i4.0. Issues such as digital capability, process integration, collaboration, and communication are the real conditions for these new technologies to achieve their maximum potential for helping companies in the current dynamic competition. One of the main cornerstones for process improvement based on maturity models is the lack of technical expertise and real technology strategy, both identified in the studied company (Machado, 2019).

Barcodes are consolidated technologies in industrial contexts since the '90s. They can be applied without integration to the company's databases or even as a tool for only input-output control in a specific area. Schuh et al. (2017) bring lights on the first steps to implement industry 4.0. These authors state that an initial effort must be made for computerizing the processes in the company, and it is a basis for a second level called connectivity. These two levels allow a company to be digitalized. Only after digitalization, some advanced technologies, 
such as big data, analytics, and artificial intelligence, can be applied to its processes. The implementation here presented is a barcode application and an integration of barcodes, EPR systems, and mobile devices supported by specialist systems to improve the decision-making process in the storage operation. This integration can enable the company to integrate other areas, such as in-house manufacturing, which is already well automatized. It also reflects a typical challenge Brazilian companies face where multiple processes are human-based and unstructured. They need to defend their markets from better systematized and digitalized companies. To do this, a few steps, like barcode integration, can bring an avenue of future improvements.

\section{CONCLUDING REMARKS}

This paper presents a real Brazilian case of industry 4.0 improvement based on a maturity model. As discussed, the implemented i4.0 technology integration helps the company save direct inventory costs and provide some basis for improvements in the integration of other company areas and its supply chain. The previous section discusses the first two research questions we have. In conclusion, we discuss the third question.

Despite the improvements presented, company managers' digitalization strategy improves one area but does not allow them to reap the improvements' potential. The phenomena of islands of improvement occur. It can, however, be understood under some dimensions of the 4Th industrial revolution. For example, digital competencies must be employed since planning new processes. Despite being well advertised, new technologies have details and possibilities, which only well-qualified professionals can in-depth enjoy.

Lacks in company integration are another dimension of improvement islands. This issue is well known and scientifically discussed. New technologies open new possibilities in terms of integration, connecting people using communication technologies, even on an informal basis, and company managers under new legal considerations can also exploit it. The same reasoning can be used concerning the collaboration issues, whether based on the consumer or the value chain's supplier side. An open mind reasoning must base these new business models' design, even under new legal considerations stated by the Agca model considered in this paper.

The main limitation of this research is the fact of being carried out on only a case study. It cannot be generalized, but our research object's explorative nature demands this kind of case study under an action research protocol. New research in new contexts and with different maturity models can help develop a science of digital transformation useful to companies in different sectors that face different market and organizational conditions. These are all future roads for research.

\section{REFERENCES}

Agca, O., Gibson, J., Godsell, J. et al. (2017), "An Industry 4 Readiness Assessment Tool", WMG; Crimson \& Co e Pinsent Mason, Warwick.

Almeida, M.S. (2011), Elaboração de Projeto, TCC, Dissertação e Tese: uma Abordagem Simples, Prática e Objetiva, Atlas, São Paulo, p. 96.

Akdil, K.Y., Ustundag, A. and Cevikcan, E. (2018), "Maturity and readiness model for Industry 4.0 strategy", in Ustundag, A. and Cevikcan, E. (Eds.), Industry 4.0: Managing the Digital Transformation, Springer, Reino Unido, pp. 61- 93.

Azanha, A., Vivaldini, M., Pires, S.R.I. et al. (2016), "Voice picking: analysis of critical factors through a case study in Brazil and the United States", International Journal of Productivity and Performance Management, Vol. 65, No. 5, pp. 723-39.

Barbalho, S.C.M. and Rozenfeld, H. (2008), "A reference model to promote performance development by focusing on capability improvement", Product: Management \& Development, Vol. 62, pp. 115-25.

Barbalho, S.C.M. and Rozenfeld, H. (2010), "O impacto dos aspectos organizacionais sobre a percepção de melhoria em desenvolvimento de produtos", Gestão \& Produção, Vol. 17, No. 1, pp. 1-17.

Barbalho, S.C.M. and Rozenfeld, H. (2013), "Modelo de referência para o processo de desenvolvimento de produtos mecatrônicos (MRM): validação e resultados de uso", Gestão \& Produção, Vol. 20, pp. 162-79. 
Cantamessa, M. and Montagna, F. (2016), Management of Innovation and Product Development: Integrating Business and Technological Perspectives, Springer, London.

Carolis, A.D., Macchi, M., Negri, E. et al. (2017), “Guiding manufacturing companies towards digitalization: a methodology for supporting manufacturing companies in defining their digitalization roadmap", in International Conference on Engineering, Technology, and Innovation: Engineering, Technology, and Innovation Management Beyond 2020: New Challenges, New Approaches, ICE/ITMC 2017 - Proceedings, IEEE, New York, pp. 487-495.

Cauchick Miguel, P.A. (2007), "Estudo de caso na Engenharia de Produção: estruturação e recomendações para sua condução", Production, Vol. 17, No. 1, pp. 216-29.

Chrissis, M.B., Konrad, M. and Shrum, S. (2003), CMMI: Guidelines or Process Integration and Product Improvement, Addison-Wesley, Boston, p. 832.

Colli, M., Berger, U., Bockholt, M. et al. (2019), "A maturity assessment approach for conceiving contextspecific roadmaps in the Industry 4.0 era", Annual Reviews in Control, Vol. 48, pp. 165-77.

Colli, M., Madsen, O., Berger, U. et al. (2018), "Contextualizing the outcome of a maturity assessment for Industry 4.0", IFAC Papers On Line, Vol. 51, No. 11, pp. 1347-52.

Dantas, R. (2019), Aplicação do modelo de maturidade de Indústria 4.0 em uma fabricante de bebidas e a implementação de um sistema de gestão de armazenagem como parte de sua estratégia digital, Projeto de Graduação em Engenharia de Produção, Universidade de Brasília, Brasília, DF, available at: https://bdm.unb.br/bitstream/10483/23104/1/2019_RafaelaDeFariaDantas_tcc.pdf (accessed 30 November 2018).

Ganzarain, J. and Errasti, N. (2016), "Three-stage maturity model in SME's towards Industry 4.0", Journal of Industrial Engineering and Management, Vol. 9, No. 5, pp. 1119-28.

Hofmann, E. and Rüsch, M. (2017), "Industry 4.0 and the current status as well as future prospects on logistics", Computers in Industry, Vol. 89, pp. 23-34.

Lichtblau, K., Stich, V., Bertenrath, R. et al. (2015), IMPULS-Industrie 4.0-Readiness, Impuls-Stiftung des VDMA, Aachen-Köln.

Machado, C.G. (2019), "Industry 4.0 readiness in manufacturing companies: challenges and enablers towards increased digitalization", Procedia CIRP, Vol. 81, pp. 1113-8.

Mello, C.H.P., Turrioni, J.B., Xavier, A.F. et al. (2012), "Pesquisa-ação na engenharia de produção: proposta de estruturação para sua condução", Produção, Vol. 22, No. 1, pp. 1-13.

Saaty, R.W. (1987), "The analytic hierarchy process-what it is and how it is used", Mathematical Modelling, Vol. 9, No. 3-5, pp. 161-76.

Saaty, T. and Vargas, L. (2012), Models, Methods, Concepts \& Applications of the Analytic Hierarchy Process, Springer Science \& Business Media, New York.

Scheer, A.W. (1991), CIM. Computer Integrated Manufacturing: Towards the Factory of the Future, SpringerVerlag, Berlin, p. 290.

Schuh, G., Gausemeier, J., Hompel, M. et al. (2017), Industrie 4.0 Maturity Index: Managing the Digital Transformation of Companies, Herbert Utz, Munich.

Schumacher, A., Erol, S. and Sihn, W. (2016), "A maturity model for assessing Industry 4.0 readiness and maturity of manufacturing enterprises", Procedia CIRP, Vol. 52, pp. 161-6.

Seidelmann, J. (2018), “Digital Transformation/Industrie 4.0”, Fraunhofer, Berlin, available at: https://www.ipa.fraunhofer.de/en/about-us/guiding-themes/industrie-4-0/definition.html (accessed 30 November 2018).

Silva, I.A., Barbalho, S.C.M., Adam, T. et al. (2019), "Industry 4.0 maturity models: a bibliometric study of scientific articles from 2001 to 2018", in 26th EurOMA Conference Operations Adding Value to Society, Aalto University, Helsinki, Vol. 1. pp. 1829-1838.

Taliaferro, A., Guenette, C.A., Agarwal, A. et al. (2016), Industry 4.0 and Distribution Centers: Transforming Distribution Operations Through Innovation, Deloitte University Press, Canada, 16 p.

Vernadat, F.B. (1996), Enterprise Modeling and Integration: Principles and Applications, Chapman \& Hall, London.

Author contributions: All authors contributed equally to this paper 